Original Research Paper

\title{
Essential Oil Chemical Composition of Myrtle Growing in Northeastern Algeria and Estimation of its Antibacterial Effectiveness
}

\author{
Barhouchi Badra, Aouadi Saoudi and Abdi Akila \\ Laboratory of Applied Biochemistry and Microbiology (LABM), Department of Biochemistry, \\ Faculty of Sciences, Badji Mokhtar University, BP12, 23000, Annaba, Algeria
}

\author{
Article history \\ Received: 04-12-2015 \\ Revised: $31-03-2016$ \\ Accepted: 02-04-2016 \\ Corresponding Author: \\ Barhouchi Badra \\ Laboratory of Applied \\ Biochemistry and Microbiology \\ (LABM), Department of \\ Biochemistry, Faculty of \\ Sciences, Badji Mokhtar \\ University, BP12, 23000, \\ Annaba, Algeria \\ Email: b.barhouchi@yahoo.fr
}

\begin{abstract}
The aim of this study is to determine the antibacterial effectiveness of leaves essential oil extracted from myrtle growing in Algeria. A cluster analysis of soil and water was effectuated for performing chemical and granulometric analyses. The essential oil was isolated from leaves by hydro distillation and analyzed by Gas Chromatography-Mass Spectrometry (GC/MS). The leaves yield reached a peak at the flowering stage $(1.14 \%)$ and a minimum in the fruiting time $(0.6 \%)$. Several compounds in the leaf essential oil were characterized including 49 components. The major compounds of the oil are $\alpha$-pinene (55\%), 1,8-cineole $(33,42 \%)$ and limonene $(33,42 \%)$. The effect of essential oil and specific antibiotics was investigated in vitro against twenty Gram-negative bacteria. The essential oil effect was colicidal with best inhibition zone $(35 \mathrm{~mm})$. This study showed that the myrtle essential oil in relation with the chemical composition of soil give a promising perspective for the production of essential oils with constant composition and specific activities.
\end{abstract}

Keywords: Myrtus communis, Essential Oil, Chemical Composition, $\alpha$ Pinene, 1,8-Cineole, Soil Analysis, Antibacterial Activity

\section{Introduction}

The problem of microbial resistance has grown significantly in the last several years due to the misuse of antibiotics and the increase of immunodeficiency (Grayer and Harborne, 1994). Nevertheless, plant extracts and natural products have been intensively investigated for their antimicrobial properties. The conventional antimicrobials from chemical synthesis, such as acetic, benzoic, lactic, propionic and sorbic acids, as well as nitrite and sulfites, have been used for many years to control the growth of microorganisms in food (Sofos et al., 1998). The absolute interdiction of chemical additives in aliments by the United States Food and Drug Administration (FDA) is due to the side effects of these chemicals on humans.

Plants have great advantages over microorganisms, making their exploitation in food or medicine more appropriate for replacing synthetic antioxidants and additives, which are being restricted due to their passivity. In addition, from a legislative point of view, it would be economically more feasible to use a whole spice or herb or a whole essential oil as an ingredient than to use essential oil component solely (Smid and Gorris, 1999). The exploitation of essential oils is expected to increase in the future because of the rise of 'green consumerism' motivating the use and development of products derived from plants for reliable applications.

Microbial contamination and food deterioration by microorganisms are an unresolved problem. It is represented, especially by Gram-negative bacteria. For instance, a large outbreak of diarrhea in Germany was caused by the most virulent strain of new Escherichia coli known to date and presented in steak. More broadly, these discoveries highlight the way in which the plasticity of bacterial genomes facilitates the emergence of new pathogens and therefore requires incessant monitoring (Rasko et al., 2011).

In Algeria, health problems are very challenging and still pose a crossroads in the scientific research field. The main objective is to discover an alternative source of safe, effective and acceptable natural preservatives. Actually, some Algerians commonly suffer from gastrointestinal disorders, such as ulcers, gastritis and infantile diarrhea. These crises are mostly caused by alimentary products that are frequently consumed in 
Algeria, particularly milk, dairy products, cheese, ice cream and eggs. The water used to wash vegetables may also contain pathogens that lead to the same problems.

Myrtle has played a key role as among the herbs used in alternative medicine. Myrtus communis is an evergreen, perennial and typical shrub belonging to the Myrtaceae family and widely spread in several regions globally, such as the Mediterranean ecosystem, the Middle East, North America and Australia (O" zek et al., 2000). In addition, this specie is a very aromatic plant that has been used traditionally because of the high essential oil content in its leaves, flowers, and fruits (De Laurentis et al., 2005). Many essential oils and extracts from various plants have been investigated for their antimicrobial properties against a series of bacteria and yeasts (Cox et al., 2001).

The quantitative composition and the relative proportions of the myrtle oil components are widely influenced by the genotype, the ontogenic development and the environmental and growing conditions. Many phytochemical studies have simultaneously investigated the essential oil composition of leaves and fruits as well as the other parts of M.communis (Jerkovic et al., 2002; Tuberoso et al., 2006). Until now, many studies on myrtle has widely focused on the composition of the volatile compounds in leaves belonging to different regions and harvested in different periods $\left(\mathrm{O}^{*}\right.$ zek et al., 2000; Asllani, 2000; Tuberoso et al., 2006). Recent studies were encouraged by the lack of reliable data on the antibacterial activity of essential oils of myrtle collected from the mountainous regions in northeastern Algeria.

The aim of this work is to characterize myrtle leaves collected from northeastern Algeria through its essential oil composition to determine its antibacterial effects and to try to valorize this myrtle part as a source of bioactive compounds. This may lead to the discovery of an analogous myrtle essential oil with a similar composition or activity. In light of the facts mentioned above, it appears necessary to evaluate the correlation between the chemical composition and the antibacterial activities of the Algerian essential oil of M.communis collected from Annaba region.

\section{Materials and Methods}

\section{Biochemical Section}

\section{Plant Material}

Fresh leaves of M.communis were collected from remote areas in the suburbs of the Annaba region (northeastern Algeria) during the vegetative, flowering and fruiting seasons (2012/2013). The taxonomic identification was performed in the Biology Department, Badji Mokhtar University, Annaba, Algeria. The leaves were then isolated from the other specimens and were dried in the shade for a week at room temperature. The dried leaves were conserved for the extraction process.

\section{Essential Oil Extraction}

The $M$. communis essential oil was extracted from 50 $\mathrm{g}$ of dried leaves after submission for $2 \mathrm{~h}$ to hydrodistillation using a Clevenger-type apparatus. This process was adopted in this study to extract the essential oil according to the method recommended in the European Pharmacopeia (2002). The essential oil was dried over anhydrous sodium sulfate. It was filtered and stored in the refrigerator $\left(4^{\circ} \mathrm{C}\right)$ until antibacterial tests against clinical pathogens were performed.

\section{Chemicals, Reagents and Solvents}

All culture media, standard antibiotic discs and dimethyl sulfoxide (DMSO) were purchased from Sigma-Aldrich. The water used was purified and distilled. All other chemicals were of analytical grade.

\section{Chemical Analysis GC/MS}

The samples of myrtle essential oil extracted from the leaves were analyzed by GC/MS using an HP 5890 series II gas chromatograph equipped with a flameionization detector and coupled to an HP 5972 mass spectrometer (Agilent Technologies) with electronimpact ionization $(70 \mathrm{eV})$ and an HP-5MS capillary column $(30 \times 0.25 \mathrm{~mm}$ coated with $5 \%$ phenyl methyl silicone, 95\% dimethylpolysiloxane; a $0.25-\mu \mathrm{m}$ film thickness were used). The operating conditions were as follows: The column temperature was programmed to rise from 50 to $240^{\circ} \mathrm{C}$ at a rate of $5^{\circ} \mathrm{C} / \mathrm{min}$, and the transfer-line temperature was $250^{\circ} \mathrm{C}$. The carrier gas was helium with a flow rate of $1.2 \mathrm{~mL} \mathrm{~min}^{-1}$ and a split ratio of 60: 1 . The scan time and mass range were $1 \mathrm{~s}$ and 40$300 \mathrm{~m} / \mathrm{z}$, respectively. The mass-spectrometer conditions were the following: Injection of $2 \mu \mathrm{L}$ aliquot of the sample and an HP-5MS capillary column $(30 \times 0.25 \mathrm{~mm}$; coating thickness, $0.25 \mu \mathrm{m}$ ).

\section{Compounds Identification}

The components of the oil were identified by a comparison of the fragmentation patterns in the mass spectra with those stored in the GC/MS databases and other published mass spectra in relation to the retention time of a homologous series of alkanes (C7-C20/C30) (Adams, 2007). In addition, the percentages of the compounds were determined from their peak areas.

\section{Ecological Section}

\section{Study Area and Raw Material}

The area is located in the state of Annaba, a town situated in the northeastern of Algeria (latitude $36^{\circ} 54^{\prime}$ $15^{\prime \prime} \mathrm{N}$, longitude $\left.7^{\circ} 45^{\prime} 07^{\prime \prime} \mathrm{E}\right)$ belonging to the 
Mediterranean area. Single-season samplings were undertaken in December, 2013 (autumn season). The sampling strategy was a random zigzagged manner in which samples of the surface soil near the trees $(0-20 \mathrm{~cm}$ depth) was collected manually from a single site at the same station using suitable, uncontaminated equipment, and then the samples were stored. The four samples were dried, ground and then homogenized. From this environment, four samples of water were chosen for measurement of the limnological variables. An aliquot of each sample was set aside for subsequent chemical and granulometric analysis.

\section{Chemicals Parameters Measurements and Granulometric Analysis}

For soil sampling, a depth of soil sample of approximately $0-20 \mathrm{~cm}$ was used for the identification and measurement of the pedogenetic horizons, aimed at obtaining a morphological description. The criterion adopted in the granulometric analysis followed the universal method of the Robinson pipette, which was proposed by the Association Française de l'Etude des Sols (AFES, 1995). In all collection samples, the $\mathrm{pH}$, electrical conductivity, percentage of moisture, minerals and organic matter of the water and soil were measured. Principal component analysis was performed to identify which variables best explained the variability of the soilanalysis results, and a cluster analysis of the mean values of the chemical (soil and water) variables was also performed, calculating the average of the four samples. The presence of carbonates in the soil materials involved the reaction of $\mathrm{HCl}$ with soil carbonates and visual observation of the gaseous loss of $\mathrm{CO}_{2}$ from the sample, as described by the U.S. Salinity Laboratory Staff. This method is not quantitative. Soils may be categorized as slightly, moderately or highly calcareous in accordance to the degree of effervescence.

\section{Microbiological Section}

\section{Bacterial Strains and Culture Conditions}

For the initial screening, eighteen pathogens and two reference strains were used to evaluate the myrtle essential oil activity in vitro. The clinical bacterial strains tested were obtained from the urine samples of patients in Annaba, Algeria. After culture enrichment, the bacterial samples were identified by standard biochemical parameters and morphological studies. Twenty Gram-negative bacteria were grown in aerobic or anaerobic cultures: Escherichia coli (EC), Klebsiella pneumoniae (KP), Klebsiella oxytoca (KO), Shigella sonnei (SS), Serratia marcescens (SM), Serratia fonticola (SF), Acinetobacter baumannii (AB), Citrobacter koseri (CK), Citrobacter freundii (CF), Enterobacter aerogenes (EA), Enterobacter cloacae (EL), Enterobacter intermedius (EI), Enterobacter sakazakii (ES), Proteus mirabilis (PM), Proteus vulgaris (PV), Morganella morganii (MM), Salmonella typhimurium (ST) and Salmonella sp. (S). In addition, two reference strains from the American-Type Culture Collection (ATCC), Escherichia coli EC® (ATCC 25922) and Klebsiella pneumonaie $\mathrm{KP}{ }^{\circledR}$ (ATCC 700603), were also tested. All of the strains were cultured after identification in nutrient agar, and they were stored frozen at $4^{\circ} \mathrm{C}$ until the antibacterial tests were performed.

\section{Preparation of Antibacterial Agents}

Suspensions of the antibacterial agents to be tested were prepared immediately prior to use by the pure and the dilute essential oils of the leaves. The use of emulsifiers, such as ethanol or tween, was avoided because these agents may reduce the antibacterial effect of plant-oil components and possess membranedisrupting activity, and especially to the crystallization of our essential oil in contact with these solvents. For this reason, the essential oil was dissolved in dimethylsulfoxide (DMSO) in equivalent concentrations (essential oil/DMSO: 50/50 v/v) and sterilized by filtration through a $0.45-\mu \mathrm{m}$ membrane filter. The concentrations required for the experiments were prepared from this stock solution.

\section{Screening of Antibacterial Activity}

Solid diffusion tests: The susceptibility of the bacteria to the essential oil was determined by an agar diffusion disc method (Prabuseenivasan et al., 2006). After the Muller Hinton Agar (MHA) had solidified, the inoculums $(\mathrm{DO} \approx 0.1 / \lambda=625 \mathrm{~nm}$ ) were streaked into agar plates using a sterile swab and were then dried at $37^{\circ} \mathrm{C}$ for $15 \mathrm{~min}$. A sterile filter disc with a 6-mm diameter (Whatman paper $\mathrm{N}^{\circ} 3$ ) was placed on the surface of the MHA. Then, $10 \mu \mathrm{L}$ of the essential oil was dropped onto each disc and left for $30 \mathrm{~min}$ at room temperature for antibacterial agent diffusion. The Petri dishes were incubated at $37^{\circ} \mathrm{C}$ for 18 to $24 \mathrm{~h}$. For quality control and comparative analysis, DMSO was used as a negative control. The effectiveness of the essential oils was calculated by measuring the diameter of the zone of bacterial-growth inhibition above the disc and the diameter was recorded in $\mathrm{mm}$. The inhibition zones produced from the essential oils were compared with the inhibition zones produced by commercial standard antibiotics. An essential oil-inducing inhibition zone $\geq 3 \mathrm{~mm}$ around the disc was considered as antibacterial. All tests were performed in triplicate.

\section{Determination of the Minimum Concentrations $M I C$ and $M B C$}

The minimum Inhibitory Concentration (MIC) was defined as the lowest concentration of the total essential oil at which the microorganism does not demonstrate visible growth (CLSI, 2006). Referring to the results of 
the MIC assay, the Minimum Bactericidal Concentration (MBC) was determined. Serial dilutions of myrtle essential oil $\left(10,5,2.5,1.25\right.$ and $\left.0.625 \mathrm{mg} \mathrm{mL}^{-1}\right)$ were made with dimethylsulfoxide (DMSO). Immediately, $10 \mathrm{uL}$ of each dilution of the essential oil were added to 9 $\mathrm{mL}$ of the MH-broth tubes, which were then incubated at $37^{\circ} \mathrm{C}$ for $24 \mathrm{~h}$ in stove. After incubation, from tubes without microbial growth, $0.1 \mathrm{~mL}$ was spread onto the nutrient agar plates. The minimum bactericidal concentrations were determined as the highest dilution at which no growth occurred definitely on the plates.

\section{Susceptibility of Antibiotics}

The twenty-one antibiotics that were used for comparison of their antibacterial effects with those of myrtle essential oil were amoxycillin (AMX, $25 \mu \mathrm{g}$ ), ampicillin (AMP, $25 \mu \mathrm{g}$ ), amikacin (AK, $30 \mu \mathrm{g}$ ), tetracyclin (TE, $30 \mu \mathrm{g}$ ), doxycyclin (DO, $30 \mu \mathrm{g}$ ), ticarcillin (TI, $75 \mu \mathrm{g}$ ), gentamycin (GEN, $10 \mu \mathrm{g}$ ), erythromycin (E, $15 \mu \mathrm{g}$ ), chloramphenicol (C, $30 \mu \mathrm{g})$, cefixim (CFM, $5 \mu \mathrm{g}$ ), ceftazidim (CAZ, $30 \mu \mathrm{g}$ ), cefalexin $(\mathrm{CN}, 30 \mu \mathrm{g})$, cefotaxim (CTX, $30 \mu \mathrm{g})$, ciprofloxacin (CIP, $25 \mu \mathrm{g}$ ), cotrimoxazol (COT, $25 \mu \mathrm{g})$, colistin (CL, $25 \mu \mathrm{g})$, nalidixic acid (NA, $30 \mu \mathrm{g}$ ), pipemidic acid (PA, $20 \mu \mathrm{g}$ ), nitroxolin (NO, $30 \mu \mathrm{g})$, ofloxacin (OFX, $10 \mu \mathrm{g}$ ) and imipenem (IMP, $10 \mu \mathrm{g}$ ). The antibiotics selected for the study to elucidate their mechanism of action by the directcontact method are listed in the results with the diameters recorded in $\mathrm{mm}$. The susceptibility of each of the twentyone standard and specific antibiotics to twenty Gramnegative bacteria was assessed by the diffusion-agar method. The level of the resistance ( $\mathrm{R} \%$ ) was calculated according to the critical diameter of inhibition for each antibiotic where each strain was represented as sensible or resistant (Cavallo, 2007).

\section{Statistical Analysis}

The data obtained from the antibacterial assays were expressed as the mean values. Statistical analysis was performed by one way Analysis of Variance (ANOVA) followed by Dunnett's or Tukey's multiple-comparisons tests using the MINITAB 16 package. The level of significance was significant when $* \mathrm{P} \leq 0.05$; highly significant when $* * \mathrm{P} \leq 0.01$ and very highly significant when $* * * \mathrm{P} \leq 0.001$. All data were reported at least in triplicate for the various assays.

\section{Results and Discussion}

\section{Essential Oil Yields}

Essential oil obtained by hydrodistillation of leaves of Myrtus communis growing wild in Algeria had a pungent odor. The maximum, intermediate and minimum yields recorded were obtained in the flowering $(1.14 \%)$, vegetative $(0.62 \%)$ and fruiting $(0.6 \%)$ stages, respectively (Fig. 1). According to Jerkovic et al. (2002) and Jamoussi et al. (2005), their results showed a strong correlation between the extraction yield and the vegetative cycle of the plant, with a maximum biosynthesis of essential oils near the blossom stage. In contrast, some authors reported that the leaf essential oils yield of myrtle did not vary significantly with the seasons (Zrira et al., 2003; Gardeli et al., 2008).

\section{Chemical Composition of the Essential Oil}

Analysis of the myrtle essential oil by GC/MS showed 49 identified compounds, presenting high fluctuations in its chemical profile (Table 1). The major components of this essential oil were $\alpha$-pinene (55\%), 1,8-cineole (33.4\%), limonene (33.4\%), geranyl acetate $(2.04 \%)$ and linalool (1.43\%). Bouzabata et al. (2010) were analyzed 27 samples of essential oils isolated from myrtle leaves of three localities of northeastern Algeria. The chemical composition of these oils was largely dominated by monoterpene hydrocarbons, with $\alpha$-pinene (40-64\%), 1,8-cineole $(10,9-29,1 \%)$ and limonene $(6,7-8,2 \%)$ being the major compounds, however with little amounts of limonene smaller than 1,8-cineole concentration.

Therefore, the differences in two main components ( $\alpha$-pinene, 1,8-cineole) of our sample and the myrtle essential oils from various origins are summarized in Fig. 2. Our results are in agreement with the findings of Jamoussi et al. (2005) who analyzed the Tunisian myrtle essential oils under GC/MS conditions and reported that the major volatile components were $\alpha$-pinene, 1,8cineole and limonene, among 39 identified compounds. However, it can be observed that Italian myrtle oil indicated the same main content (Cannas et al., 2013) in according with French myrtle oil which contained 14 compounds and showed also $\alpha$-pinene and 1,8-cineole together representing around $86 \%$ (Curini et al., 2003).

In contrast, myrtenyl acetate was also the specific chemotype of the Croatian (Jerkovic et al., 2002), Greek (Gardeli et al., 2008), Spanish (Boelens and Jimenez, 1992) and Moroccan (Chalchat et al., 1998) myrtle essential oils, whereas in the present study, this compound was detected only in a low percentage in the leaf essential oil and did not exceed $0.03 \%$ in this variety. In various previous studies, Mahboubi's group studied the essential oils of Turkish myrtle, which presented a higher fraction of linalool and linalyl acetate, in disagreement with the compositions of our samples, and the Turkish findings illustrated a different chemical profile of myrtle growing in the Mediterranean area (Mahboubi and Ghazian Bidgoli, 2010). Otherwise, the essential oil of $M$. communis was established in Italian report to consist approximately of monoterpene hydrocarbons $(58.3 \%)$, mainly a $\alpha$-terpinene $(51.8 \%)$; oxygenated monoterpenes $(38.3 \%)$ represented primarily 
by 1,8 -cineole $(35.6 \%)$; and small quantities of aldehydes $(1.5 \%)$ and sesquiterpene hydrocarbons $(1.2 \%)$ while $\alpha$-pinene was not found in its chemical profile (Deriu et al., 2007).

Our results are influenced by several variables, such as the difference in myrtle essential oils yield or composition, which is due to the intervention of many important factors. Scora (1973) reported that environmental factors, such as the geographical location, temperature, day length and nutrients, were considered to play a key role in the chemical composition of myrtle oil. This leads to the existence of different chemotypes that differentiate the myrtle oil of different origins (Chalchat et al., 1998; Flamini et al., 2004) in according with the suggestion of Shu and Lawrence concerning the dependence of oil composition on the plant species, the chemotypes and the climatic conditions (Shu and Lawrence, 1997).

Several authors have even suggested that certain compounds, such as $\alpha$-pinene, camphene, 1,8-cineole and geraniol, can be regarded as regional markers able to facilitate species-improvement research by studies on isoenzymatic polymorphism because there was a positive correlation between the variation of these compounds and the distribution of particular alleles due to the various enzymatic and chemical parameters, making it possible to select genotypes and enact elaborate conservation strategies (Messaoud et al., 2005). It can be deducted that the strong chemical variability in myrtle oils can be ascribed not only to the geographical origin of the sample and its environmental conditions but also to the variety type and genetic factors (Flamini et al., 2004).

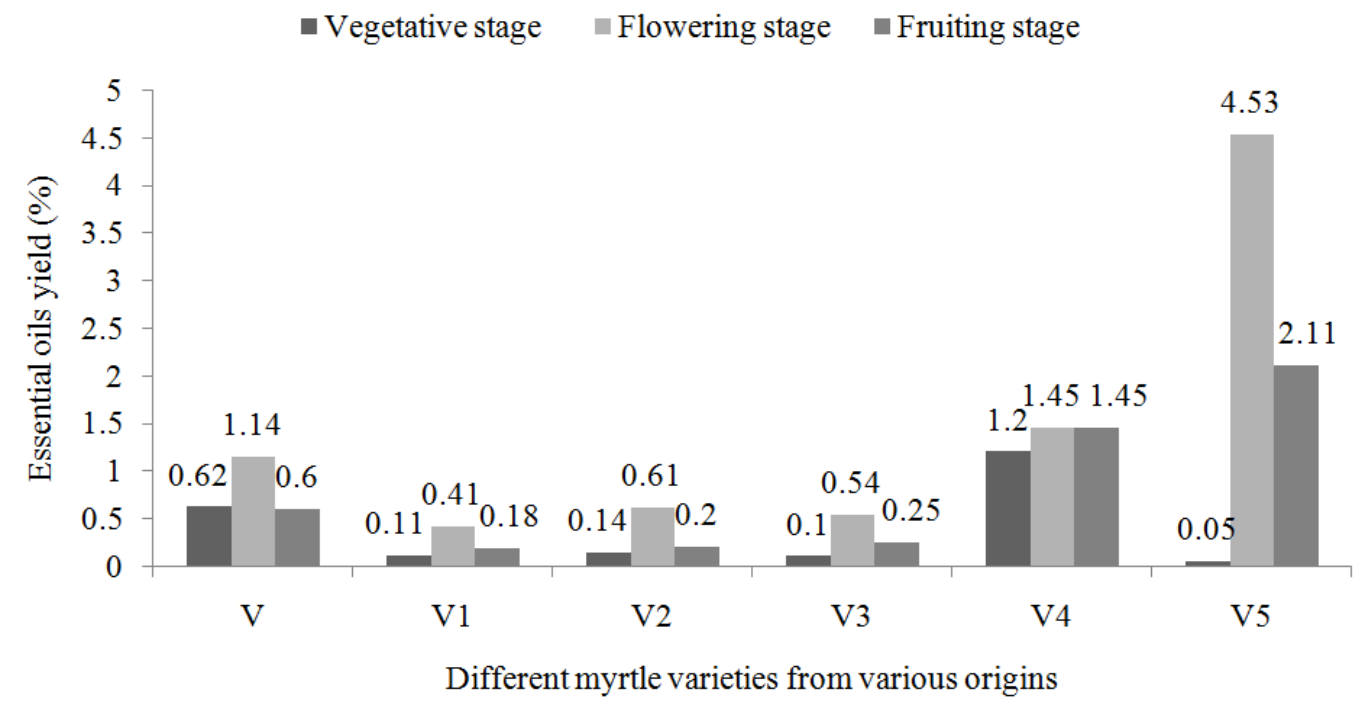

Fig. 1. Investigation of different myrtle leaves essential oils yields during successive stages of development (vegetative, flowering and fruiting periods). V: Sample studied (Algerian myrtle essential oil from leaves. V1, V2 and V3 (3 varieties of Tunisian myrtle leaves essential oils). V4 (Greek myrtle leaf essential oil). V5: Italian myrtle leaf essential oil. (Jamoussi et al., 2005; Aidi Wannes et al., 2008; Gardeli et al., 2008; Dell'Agli et al., 2012)

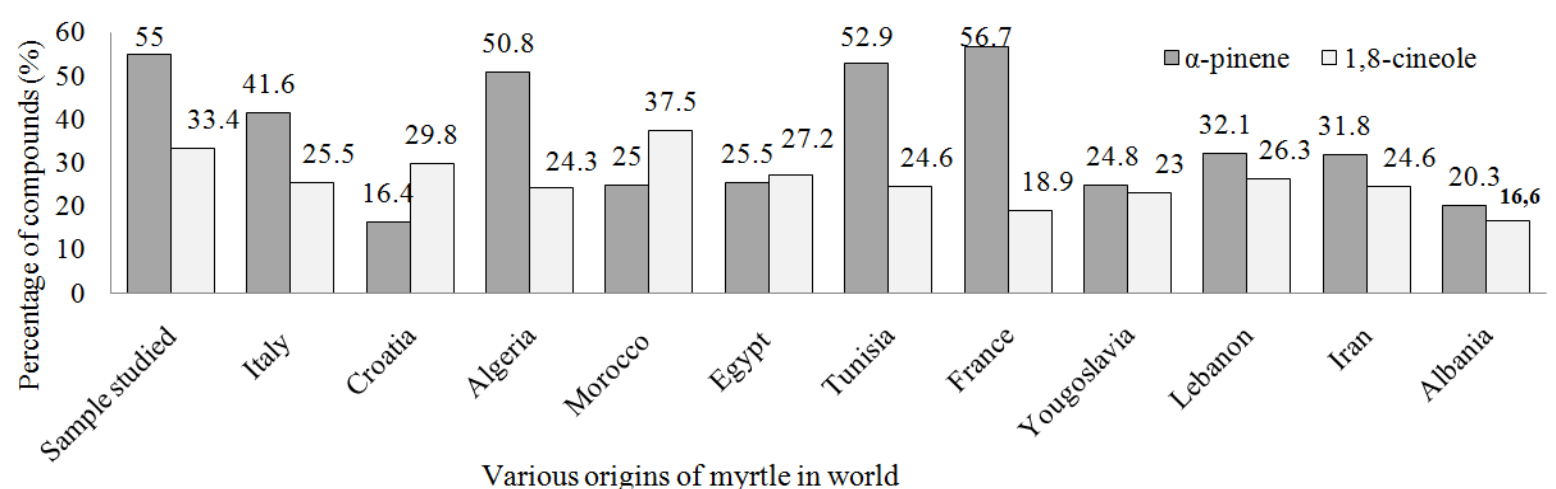

Fig. 2. Recaputilative of percentage composition of two main compounds in myrtle leaves oils from various origins, (Chalchat et al., 1998; Asllani., 2000; Jerkovic et al., 2002; Flamini et al., 2004; Ghasemi et al., 2010; Berka-Zougali et al., 2010; Nassar et al., 2010) 
Table 1. Chemical composition of leaves essential oil of myrtle

\begin{tabular}{|c|c|c|c|c|c|c|}
\hline Peak & Compound & $\mathrm{RT}(\min )$ & Area $(\%)$ & RI & MM & MF \\
\hline 1 & Isobutyl isobutyrate & 7.963 & 0.19 & 807 & 144.21 & $\mathrm{C}_{8} \mathrm{H}_{16} \mathrm{O}_{2}$ \\
\hline 2 & Alpha-pinene & 8.676 & 55.00 & 925 & 136.23 & $\mathrm{C}_{10} \mathrm{H}_{16}$ \\
\hline 3 & Camphene & 8.935 & 0.76 & 968 & 136.23 & $\mathrm{C}_{10} \mathrm{H}_{16}$ \\
\hline 4 & 1-(Methylencyclopropyl)-1-cyclopentene & 9.099 & $\operatorname{tr}$ & 995 & 120.19 & $\mathrm{C}_{9} \mathrm{H}_{12}$ \\
\hline 5 & Beta-pinene & 9.751 & 0.38 & 1103 & 136.23 & $\mathrm{C}_{10} \mathrm{H}_{16}$ \\
\hline 6 & Ethylidene cyclopropane & 10.265 & $\operatorname{tr}$ & 1188 & 68.11 & $\mathrm{C}_{5} \mathrm{H}_{8}$ \\
\hline 7 & Isobutyl-2-methylbutyrate & 10.597 & 0.22 & 1243 & 158.24 & $\mathrm{C}_{9} \mathrm{H}_{18} \mathrm{O}_{2}$ \\
\hline 8 & Delta-3-carene & 10.784 & 0.25 & 1274 & 136.23 & $\mathrm{C}_{10} \mathrm{H}_{16}$ \\
\hline 9 & Isoamyl isobutyrate & 11.044 & 0.10 & 1317 & 158.24 & $\mathrm{C}_{9} \mathrm{H}_{18} \mathrm{O}_{2}$ \\
\hline 10 & Limonene & 11.54 & 33.42 & 1399 & 136.23 & $\mathrm{C}_{10} \mathrm{H}_{16}$ \\
\hline 11 & 1,8-cineole & 11.54 & 33.42 & 1399 & 154.24 & $\mathrm{C}_{10} \mathrm{H}_{18} \mathrm{O}$ \\
\hline 12 & Gamma-terpinene & 12.301 & 0.16 & 1525 & 136.23 & $\mathrm{C}_{10} \mathrm{H}_{16}$ \\
\hline 13 & Alpha-terpinolene & 13.177 & 0.12 & 1670 & 136.23 & $\mathrm{C}_{10} \mathrm{H}_{16}$ \\
\hline 14 & Linalool & 13.648 & 1.43 & 1748 & 154.24 & $\mathrm{C}_{10} \mathrm{H}_{18} \mathrm{O}$ \\
\hline 15 & Ethylbutyl acetylene & 14.041 & $\operatorname{tr}$ & 1813 & 110.19 & $\mathrm{C}_{8} \mathrm{H}_{14}$ \\
\hline 16 & $\alpha$-Campholenal & 14.325 & $\operatorname{tr}$ & 1860 & 152.24 & $\mathrm{C}_{10} \mathrm{H}_{16} \mathrm{O}$ \\
\hline 17 & Pinocarveol & 14.754 & 0.24 & 1931 & 152.24 & $\mathrm{C}_{10} \mathrm{H}_{16} \mathrm{O}$ \\
\hline 18 & Cis-verbenol & 14.947 & $\operatorname{tr}$ & 1963 & 152.24 & $\mathrm{C}_{10} \mathrm{H}_{16} \mathrm{O}$ \\
\hline 19 & Cycloocta-1,4-dien-3-one & 15.376 & $\operatorname{tr}$ & 2034 & 108.18 & $\mathrm{C}_{8} \mathrm{H}_{12}$ \\
\hline 20 & 4-Terpineol & 15.908 & 0.15 & 2122 & 154.24 & $\mathrm{C}_{10} \mathrm{H}_{18} \mathrm{O}$ \\
\hline 21 & Linalyl propionate & 16.367 & 1.20 & 2198 & 210.31 & $\mathrm{C}_{13} \mathrm{H}_{22} \mathrm{O}_{2}$ \\
\hline 22 & Linalyl acetate & 18.017 & 0.44 & 2471 & 196.29 & $\mathrm{C}_{12} \mathrm{H}_{20} \mathrm{O}_{2}$ \\
\hline 23 & Geraniol & 18.137 & 0.25 & 2491 & 154.24 & $\mathrm{C}_{10} \mathrm{H}_{18} \mathrm{O}$ \\
\hline 24 & Myrtenyl acetate & 19.249 & $\operatorname{tr}$ & 2675 & 194.27 & $\mathrm{C}_{12} \mathrm{H}_{18} \mathrm{O}_{2}$ \\
\hline 25 & 2,6-Dimethylene-7-octen-3-one & 19.932 & $\operatorname{tr}$ & 2788 & 150.21 & $\mathrm{C}_{10} \mathrm{H}_{14} \mathrm{O}$ \\
\hline 26 & Exo-2-hydroxycineole acetate & 20.367 & $\operatorname{tr}$ & 2860 & 212.28 & $\mathrm{C}_{12} \mathrm{H}_{20} \mathrm{O}_{3}$ \\
\hline 27 & Isohexane & 20.596 & 0.64 & 2898 & 86.17 & $\mathrm{C}_{6} \mathrm{H}_{14}$ \\
\hline 28 & Neryl acetate & 20.965 & 0.16 & 2959 & 196.29 & $\mathrm{C}_{12} \mathrm{H}_{20} \mathrm{O}_{2}$ \\
\hline 29 & Geranyl acetate & 21.491 & 2.04 & 3046 & 196.29 & $\mathrm{C}_{12} \mathrm{H}_{20} \mathrm{O}_{2}$ \\
\hline 30 & Methyleugenol & 22.137 & 0.64 & 3153 & 178.22 & $\mathrm{C}_{11} \mathrm{H}_{14} \mathrm{O}_{2}$ \\
\hline 31 & Beta-caryophyllene & 22.445 & 0.29 & 3204 & 204.35 & $\mathrm{C}_{15} \mathrm{H}_{24}$ \\
\hline 32 & Alpha-humulene & 23.315 & $\operatorname{tr}$ & 3348 & 204.35 & $\mathrm{C}_{15} \mathrm{H}_{24}$ \\
\hline 33 & 1-(2,6,6-Trimethyl-1-cyclohexen-1-yl)ethanol & 23.424 & $\operatorname{tr}$ & 3366 & 84.14 & $\mathrm{C}_{4} \mathrm{H}_{4} \mathrm{~S}$ \\
\hline 34 & Germacrene-D & 24.004 & 0.11 & 3462 & 204.35 & $\mathrm{C}_{15} \mathrm{H}_{24}$ \\
\hline 35 & 3-Ethyl-3-methyl-2-pentanol & 24.379 & $\operatorname{tr}$ & 3524 & 130.22 & $\mathrm{C}_{8} \mathrm{H}_{18} \mathrm{O}$ \\
\hline 36 & Cinerolone & 24.910 & 0.13 & 3612 & 166.22 & $\mathrm{C}_{10} \mathrm{H}_{14} \mathrm{O}_{2}$ \\
\hline 37 & Artemisia acetate & 25.472 & 0.12 & 3705 & 196.28 & $\mathrm{C}_{12} \mathrm{H}_{20} \mathrm{O}_{2}$ \\
\hline 38 & Germacrene B & 25.841 & 0.10 & 3766 & 204.35 & $\mathrm{C}_{15} \mathrm{H}_{24}$ \\
\hline 39 & Caryophyllene oxide & 26.481 & 0.55 & 3872 & 220.35 & $\mathrm{C}_{15} \mathrm{H}_{24} \mathrm{O}$ \\
\hline 40 & 2-Methyl-2-cyclopentenone & 27.098 & 0.13 & 3974 & 96.12 & $\mathrm{C}_{6} \mathrm{H}_{8} \mathrm{O}$ \\
\hline 41 & P-Pentyloxynitrobenzene & 27.224 & $\operatorname{tr}$ & 3995 & 209.24 & $\mathrm{C}_{11} \mathrm{H}_{15} \mathrm{NO}_{3}$ \\
\hline 42 & Cubebene & 27.406 & $\operatorname{tr}$ & 4025 & 204.35 & $\mathrm{C}_{15} \mathrm{H}_{24}$ \\
\hline 43 & Patchulane & 27.690 & $\operatorname{tr}$ & 4072 & 206.36 & $\mathrm{C}_{15} \mathrm{H}_{26}$ \\
\hline 44 & Adamantane & 27.768 & 0.16 & 4085 & 136.23 & $\mathrm{C}_{10} \mathrm{H}_{16}$ \\
\hline 45 & 4,5-Diethyloctane & 28.227 & 0.14 & 4161 & 170.33 & $\mathrm{C}_{12} \mathrm{H}_{26}$ \\
\hline 46 & Cis-8-methylenebicyclo(5.1.0)octan & 28.590 & $\operatorname{tr}$ & 4221 & 122.20 & $\mathrm{C}_{9} \mathrm{H}_{14}$ \\
\hline 47 & (-)-Pinane-3-carboxylic acid & 28.663 & $\operatorname{tr}$ & 4233 & 182.25 & $\mathrm{C}_{11} \mathrm{H}_{18} \mathrm{O}_{2}$ \\
\hline 48 & (N-propyl)-1,2,4-triazole & 28.983 & $\operatorname{tr}$ & 4286 & 243.96 & $\mathrm{C}_{6} \mathrm{H}_{12} \mathrm{Br}_{2}$ \\
\hline \multirow[t]{2}{*}{49} & 2-Butanoylthiazole & 29.490 & $\operatorname{tr}$ & 4370 & 155.21 & $\mathrm{C}_{7} \mathrm{H}_{9} \mathrm{NOS}$ \\
\hline & Identified compounds (\%) & & 99.52 & & & \\
\hline
\end{tabular}

RT (min): Retention time in minute, Area (\%): Percentage of each compound, RI: Retention indices. MM: Molecular Mass (g/mol). MF: Molecular formula. tr: Traces $<0,1 \%$

In the end of this comparison between the chemical composition of our leaves essential oil and the various oils previously studied, it can be concluded that the most analogous oils are the Tunisian oils obtained from the leaves of two
M.communis varieties (baetica and italica), which contained 49 compounds, with $\alpha$-pinene as the predominant component (Aidi wannes et al., 2008). Subsequently, the Italian oil also has a chemical profile that is closely analogous to that of our oil, 
combining the same major components (Zanetti et al., 2010). In a practical sense, this homology was related with the content (major and negligible minor components of all compared essential oils extracted from the myrtle leaves) and is most likely due to the close connection between the soil types, edaphic factors and climate effects, and it may also be connected to the infrastructural area of the Algeria, Tunisia and Italy triangle before the continental division of Africa and Europe.

\section{Ecological Study}

Many authors such as Flamini et al. (2004) reported that the type of soil played an important role in the essential oils composition variation. These facts encouraged our research to analyze the soil and surface water of one station where the myrtle leaves were sampled manually during a single season (autumn season). After designing and performing experiments on the soil and water from our sampling location, a description of the chemical parameters and the granulometric analysis was presented in Table 2. However, the results showed data obtained from the granulometric analysis of the sediment when the site had diversity in soil composition, with $57.35 \%$ sand and $42.64 \%$ mud, which was divided into silt and clay. The results showed that the water is most fresh when the environment was rich neither in minerals nor in organic matter. In addition, the soil is acidic with a high proportion of sand $(57,35 \%)$ indicating siliceous soil type.

In disagreement with our results, the Italian research detected linalool, linalyl acetate and trans-myrtanol acetate in greater amounts in leaves essential oil of myrtle growing in siliceous soils, which demonstrated an important variation in the chemical profile of the myrtle essential oils of the two localities in comparison with myrtle growing in calcareous soil (Flamini et al., 2004). In our case, $\alpha$-pinene, 1,8 cineole and limonene (Table1) were detected in high levels in the siliceous soil. It would be interesting to follow a variety of myrtle grown on a particular soil with goal of producing the essential oils with a constant composition and, consequently, having a specific biologic activity. It is a long and difficult work that our laboratory hopes to achieve because we observed that the essential oils treated by the literature had very different compositions.

\section{Antibacterial Activity Study}

Extracts and essential oils of myrtle have been extensively tested against a broad spectrum of bacteria, fungi, yeasts, insects and parasites. They are mixtures of various lipophilic and volatile substances, such as monoterpenes, sesquiterpenes and/or phenylpropanoids. Therefore, one of the most striking features of this disparity of the myrtle essential oils effectiveness is its relationship with the active ingredients, including $\alpha$ - pinene and 1,8-cineole, which were reported as a major contributor to imparting a antimicrobial effect on E. coli, S. aureus and C. albicans (Cox et al., 2001). Several works claim that oxygenated terpenes, such as 1,8cineole, linalool, and $\alpha$-terpineol, exhibit powerful antibacterial activity (Randrianarivelo et al., 2009). However, limonene was also active against Gram positive and Gram negative bacteria (Pepeljnjak et al., 2005). These characteristics make it a perfect model of study which was carried to determine the antibacterial activity of Algerian myrtle essential oil extracted from leaves against clinical strains displaying primary resistance to some antibiotics. In Algeria, the majority of human infections are particularly provoked by the consumption of contaminated food, especially by Salmonella sp. and Escherichia coli, which represent the most food-borne Gram-negative bacteria that are frequently distributed in nature as well as in a large number of Algerian aliments.

The results for the antibiotics tested are summarized in (Table 3), which showed strong activity (40-mm zone) and weak inhibition (6-8-mm zone). Ampicillin and third-generation ceftazidim did not produce good zones for inhibition with the Gramnegative bacteria, which revealed the highest level of resistance at $90 \%$ (Fig. 3). As results, the antibacterial bioassays of the essential oil are summarized in (Table 4), where it is obvious that the myrtle essential oil of leaves showed moderate to strong antibacterial activity and the diameters of the inhibition zones ranged from 08-35 mm. According to the estimated diameters, the highest activity was observed against $E$. coli with inhibition zone $(35 \mathrm{~mm})$ recorded for the fresh essential oil isolated from the leaves. The MIC values ranged from 0.6 to $2.5 \mathrm{mg} \mathrm{mL}^{-1}$, but the $\mathrm{MBC}$ tests indicated the entire bacteriostatic effect of our essential oils, which is demonstrated by the remarkable growth that occurred on the plates.

The inhibitory effect of different concentrations of oil on microbial growth varied with bacteria (Kivanc and Akgul, 1986). All the assayed essential oils significantly inhibited the growth of at least some of the bacterial strains tested. With comparison to both of diluted and undiluted oils; it is evident from the results that the inhibitory effect of diluted oil was moderately weak on all strains.

Based on these finding, the results summarized in the (Table 4) agreed with previous studies where myrtle essential oils demonstrated approximately weak inhibitory effects against Proteus vulgaris. It is also attributable to validate the slight activity in vitro of both the Turkish and the Italian oils towards the same strain while there was no activity of the Egyptian myrtle essential oil detected against Proteus vulgaris (Aboutabl et al., 2013; Senatore et al., 2013). 


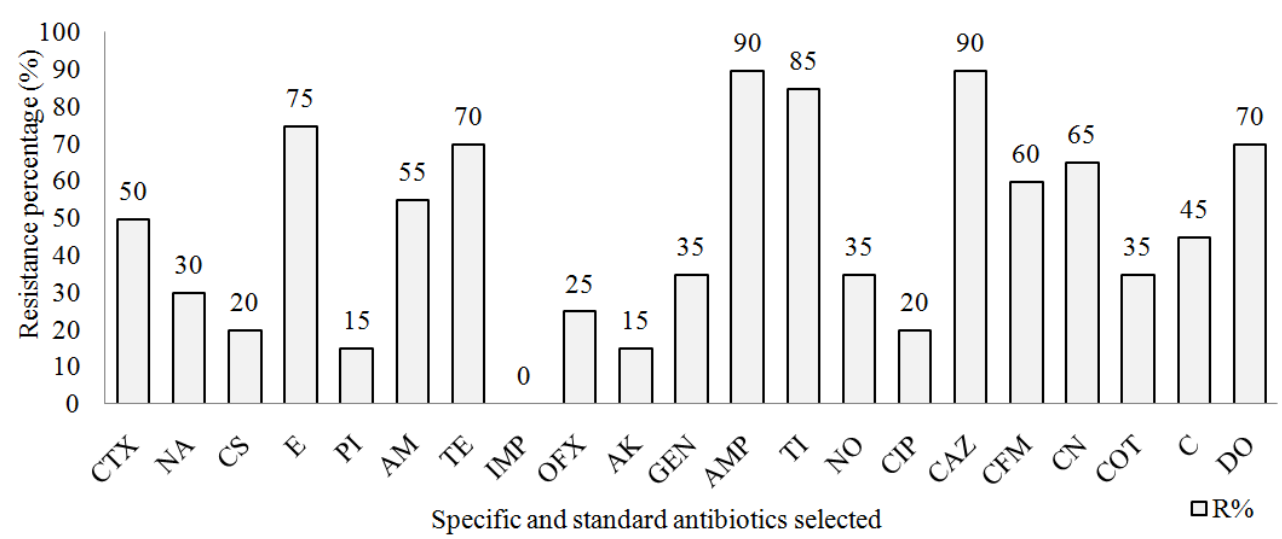

Fig. 3. Resistance percentage of selected antibiotics against Gram negative bacteria, AMX (Amoxycillin), AMP (Ampicillin), AK (Amikacin), TE (Tetracyclin), DO (Doxycyclin), TI (Ticarcillin), GEN (Gentamycin), E (Erythromycin), C (Chloramphenicol), CFM (Cefixim), CAZ (Ceftazidim), CN (Cefalexin), CTX (Cefotaxim), CIP (Ciprofloxacin), COT (Cotrimoxazol), CL (Colistin), NA (Nalidixic acid), PA (Pipemidic acid), NO (Nitroxolin), OFX (Ofloxacin), IMP (Imipenem)

Table 2. Chemical parameters measurements and granulometric analysis (water and soil of one sampling location)

\begin{tabular}{lll}
\hline & Parameters & Values \\
\hline Water & Humidity (\%) & 99.91 \\
& Organic matter (\%) & 0.015 \\
& Minerals (\%) & 0.068 \\
pH & Conductivity $(\mu \mathrm{s})$ & 7 \\
Soil & Humidity (\%) & 476 \\
& Organic matter (\%) & 2.8 \\
& Minerals (\%) & 7.8 \\
& pH & 89.6 \\
& Conductivity $(\mu \mathrm{s})$ & 6.65 \\
& Clay (\%) & 103 \\
& Silt (\%) & 38.38 \\
& Sand (\%) & 4.26 \\
& DSS: Depth of soil sample $(\mathrm{cm})$ & 57.35 \\
& Soil + HCl 3N & {$[0-20]$} \\
& & No effervescence \\
\hline
\end{tabular}

Table 3. Selected antibiotics susceptibility to twenty Gram negative bacteria (Diameter of inhibition zones in $\mathrm{mm}$ )

\begin{tabular}{|c|c|c|c|c|c|c|c|c|c|c|c|c|c|c|c|c|c|c|c|c|c|}
\hline & CTX & NA & $\mathrm{CS}$ & E & PI & $\mathrm{AM}$ & TE & IMP & OFX & $\mathrm{AK}$ & GEN & AM & TI & $\mathrm{NO}$ & CIP & CAZ & CFM & $\mathrm{CN}$ & COT & $\mathrm{C}$ & DO \\
\hline$\overline{\mathrm{EC}(\mathbb{R}}$ & 29 & 31 & 18 & 18 & 29 & 16 & 20 & 33 & 30 & 30 & 30 & 5 & 25 & 30 & 20 & 10 & 19 & 19 & 31 & 34 & 26 \\
\hline$K P ®$ & 20 & 21 & 20 & 8 & 19 & 5 & 15 & 33 & 18 & 28 & 19 & 5 & 5 & 15 & 21 & 5 & 8 & 5 & 20 & 13 & 14 \\
\hline $\mathrm{AB}$ & 5 & 5 & 15 & 17 & 5 & 5 & 8 & 33 & 5 & 23 & 11 & 5 & 15 & 8 & 5 & 5 & 5 & 5 & 5 & 14 & 13 \\
\hline $\mathrm{CK}$ & 30 & 29 & 16 & 13 & 30 & 25 & 6 & 38 & 16 & 24 & 20 & 20 & 9 & 30 & 40 & 14 & 26 & 16 & 5 & 28 & 7 \\
\hline $\mathrm{CF}$ & 36 & 31 & 6 & 13 & 27 & 6 & 7 & 32 & 30 & 25 & 22 & 6 & 30 & 25 & 35 & 16 & 34 & 20 & 30 & 27 & 6 \\
\hline $\mathrm{EC}$ & 27 & 24 & 16 & 11 & 23 & 20 & 5 & 27 & 27 & 25 & 21 & 7 & 7 & 29 & 30 & 6 & 26 & 6 & 32 & 30 & 6 \\
\hline EA & 5 & 5 & 17 & 5 & 5 & 16 & 5 & 30 & 8 & 23 & 21 & 6 & 7 & 28 & 36 & 15 & 27 & 10 & 24 & 25 & 17 \\
\hline EL & 6 & 8 & 16 & 18 & 20 & 6 & 13 & 33 & 24 & 27 & 8 & 6 & 6 & 6 & 44 & 6 & 6 & 6 & 6 & 8 & 13 \\
\hline EI & 25 & 6 & 17 & 6 & 5 & 20 & 5 & 30 & 8 & 30 & 19 & 14 & 19 & 26 & 40 & 6 & 6 & 6 & 6 & 11 & 22 \\
\hline ES & 30 & 28 & 17 & 20 & 30 & 6 & 25 & 47 & 33 & 24 & 22 & 6 & 6 & 6 & 30 & 14 & 21 & 6 & 6 & 10 & 18 \\
\hline KP & 28 & 25 & 20 & 5 & 30 & 24 & 5 & 34 & 32 & 26 & 16 & 6 & 6 & 30 & 34 & 6 & 6 & 6 & 34 & 32 & 10 \\
\hline $\mathrm{KO}$ & 30 & 5 & 20 & 10 & 20 & 30 & 21 & 25 & 30 & 28 & 21 & 7 & 6 & 30 & 30 & 12 & 25 & 6 & 30 & 30 & 8 \\
\hline MM & 14 & 5 & 20 & 10 & 10 & 6 & 40 & 40 & 36 & 6 & 6 & 7 & 6 & 25 & 27 & 6 & 6 & 24 & 35 & 28 & 8 \\
\hline PM & 36 & 30 & 5 & 7 & 30 & 30 & 5 & 32 & 30 & 24 & 17 & 6 & 6 & 24 & 38 & 19 & 32 & 20 & 34 & 27 & 8 \\
\hline PV & 20 & 23 & 25 & 25 & 28 & 6 & 8 & 32 & 34 & 7 & 7 & 6 & 6 & 6 & 40 & 10 & 20 & 6 & 6 & 13 & 8 \\
\hline $\mathrm{S}$ & 7 & 7 & 20 & 7 & 5 & 10 & 5 & 32 & 11 & 23 & 15 & 6 & 6 & 26 & 16 & 6 & 6 & 6 & 15 & 27 & 9 \\
\hline ST & 5 & 36 & 16 & 16 & 30 & 5 & 25 & 30 & 35 & 25 & 13 & 5 & 5 & 7 & 37 & 5 & 5 & 5 & 5 & 12 & 20 \\
\hline SS & 33 & 30 & 20 & 5 & 28 & 8 & 30 & 32 & 35 & 22 & 20 & 7 & 7 & 27 & 30 & 15 & 23 & 6 & 16 & 16 & 20 \\
\hline SM & 30 & 25 & 6 & 15 & 30 & 20 & 6 & 35 & 30 & 27 & 26 & 6 & 27 & 29 & 40 & 19 & 25 & 16 & 33 & 30 & 19 \\
\hline SF & 14 & 23 & 8 & 13 & 30 & 6 & 8 & 30 & 32 & 7 & 7 & 6 & 6 & 6 & 40 & 10 & 19 & 6 & 6 & 10 & 6 \\
\hline
\end{tabular}

Bacterial strains: Escherichia coli (EC), Klebsiella pneumonia (KP), Klebsiella oxytoca (KO), Shigella sonnei (SS), Serratia marcescens (SM), Serratia fonticola (SF), Acinetobacter baumannii (AB), Citrobacter koseri (CK), Citrobacter freundii (CF), Enterobacter aerogenes (EA), Enterobacter cloacae (EL), Enterobacter intermedius (EI), Enterobacter sakazakii (ES), Proteus mirabilis (PM), Proteus vulgaris (PV), Morganella morganii (MM), Salmonella typhimurium (ST) and Salmonella sp. (S). Escherichia coli (EC®), Klebsiella pneumonaie (KP $\left.{ }^{\circledR}\right)$.

Antibiotics: AMX (Amoxycillin), AMP (Ampicillin), AK (Amikacin), TE (Tetracyclin), DO (Doxycyclin), TI (Ticarcillin), GEN (Gentamycin), E (Erythromycin), C (Chloramphenicol), CFM (Cefixim), CAZ (Ceftazidim), CN (Cefalexin), CTX (Cefotaxim), CIP (Ciprofloxacin), COT (Cotrimoxazol), CL (Colistin), NA (Nalidixic acid), PA (Pipemidic acid), NO (Nitroxolin), OFX (Ofloxacin), IMP (Imipenem). 
Table 4. Antibacterial activity of myrtle essential oil (leaves) against different strains bacteria ( $\mathrm{mm}$ ) with MIC results (mg/ml)

\begin{tabular}{|c|c|c|c|c|}
\hline Strain & Symbol & Undiluted EO & Dilute EO $(* *)$ & $\operatorname{MIC}(\mathrm{mg} / \mathrm{ml})(* * *)$ \\
\hline$\overline{\text { Escherichia coli } \AA}$ & $E C \AA$ & 25 & 09 & 2.50 \\
\hline Klebsiella pneumonia ${ }^{\circledR}$ & $\mathrm{KP} \circledast$ & 09 & 07 & 2.50 \\
\hline Acinetobacter baumannii & $\mathrm{AB}$ & 09 & 05 & 1.25 \\
\hline Citrobacter freundii & $\mathrm{CF}$ & 09 & 05 & 2.50 \\
\hline Citrobacter koseri & $\mathrm{CK}$ & 08 & 05 & 2.50 \\
\hline Escherichia coli & $\mathrm{EC}$ & 35 & 10 & 1.25 \\
\hline Enterobacter aerogenes & EA & 10 & 10 & 0.60 \\
\hline Enterobacter cloacae & EL & 10 & 07 & 1.25 \\
\hline Enterobacter intermedius & EI & 10 & 08 & 1.25 \\
\hline Enterobacter sakazakii & $\mathrm{ES}$ & 10 & 07 & 1.25 \\
\hline Klebsiella pneumonaie & KP & 09 & 05 & 1.25 \\
\hline Klebsiella oxytoca & $\mathrm{KO}$ & 10 & 05 & 2.50 \\
\hline Morganella morganii & MM & 08 & 05 & 1.25 \\
\hline Proteus mirabilis & PM & 09 & 05 & 2.50 \\
\hline Proteus vulgaris & PV & 11 & 07 & 0.60 \\
\hline Salmonella sp. & $\mathrm{S}$ & 08 & 05 & 1.25 \\
\hline Salmonella typhimurium & $\mathrm{ST}$ & 10 & 09 & 1.25 \\
\hline Shigella sonnei & SS & 10 & 09 & 0.60 \\
\hline Serratia marcescens & SM & 09 & 05 & 1.25 \\
\hline Serratia fonticola & SF & 09 & 09 & 1.25 \\
\hline Negative control & DMSO & - & - & - \\
\hline
\end{tabular}

(05): No zone inhibition, (EO): Essential Oil, (MIC): Minimal Inhibition Concentration, ®): Reference strain, (DMSO): Dimethylsulfoxide, $(* *): \mathrm{p} \leq 0.01,(* * *): \mathrm{p} \leq 0.001$

However, the results clearly indicated that the Salmonella sp. susceptibility to myrtle oils appears in an inhibition zone lower than those found in literature; this in agreement with previous reports by the several workers in North Cyprus (Akin et al., 2010). This ubiquitous environmental bacterium presented a slight activity that was achieved by Italian and Turkish myrtle essential oils (Senatore et al., 2013). In contrast, this Gram-negative bacterium was the most sensitive one to both the oils of Algerian and Tunisian populations, with high vulnerability to M.communis oil attack under static circumstances (Ben Ghnaya et al., 2013).

Many studies have proved the synergistic effect of essential oils or their fractions from different plants with synthetic drugs as antifungal and antibacterial agents particularly eucalyptol, geraniol were established to interact synergistically with norfloxacin against $B$. subtilis, B. cereus, S. aureus, and E. coli (Rosato et al., 2007). Interestingly, synergistic effects of the combinations of 1,8-cineole and aromadendrene against MethicillinResistant Staphylococcus Aureus (MRSA) and Vancomycin-Resistant Enterococci (VRE) and Enterococcus faecalis by using checkerboard and time-kill assays respectively were reported (Mulyaningsih et al., 2010). Other combinations including a monoterpene hydrocarbon ( $\alpha$-pinene) with limonene or linalool also showed additive and synergistic effects (Tserennadmid et al., 2011). In addition, In vitro synergistic efficacy of combination of amphotericin B with Myrtus communis essential oil against clinical isolates of Candida albicans was also performed to explore the opportunity of emerging a more powerful combination therapy (Mahboubi and Ghazian Bidgoli, 2010). The interaction between essential oils and microbes which ultimately induces the antimicrobial activity is not well understood. Hitherto, different target sites and mode of action are discussed. Based on these results, it was assumed that the essential oils may have antimicrobial activity by influencing bacterial and fungal targets involved in cytoplasmatic and cell wall metabolism. It is stated by several researchers that especially monoterpenes will increase cytoplasmic membrane fluidity and permeability, disturb the order of membrane embedded proteins, inhibit cell respiration, and alter ion transport processes (Reichling et al., 2009).

Besides, most of the studies on the incidence of a synergistic interaction between the essential oil and their phenolic constituents have concentrated on their effects on cell walls and cell membranes that are known to provoke damage to each structure, which disintegrates the external membrane of Gram-negative bacteria. They represented also by releasing lipopolysaccharides, increasing the permeability of the cytoplasmic membrane to ATP, causing leakage of cellular materials, and ultimately the bacteria death but also by influencing the membrane functions such as electron transport, enzyme activity or nutrient uptake (Amensour et al., 2010). Further studies concerning the antibacterial activity and the mode of action of myrtle essential oils are in progress.

\section{Conclusions and Perspectives}

The correlation between the chemical composition of the myrtle essential oil and its potent antibacterial 
activity could be useful in the search for novel active compounds, and these findings may partially validate the alternative use of this plant, but further in vivo and clinical studies are required to justify the rationale of its traditional exploitation scientifically. Currently, the rapid growth of Myrtus communis makes it a promising candidate as a valuable natural resource for the commercial production of drugs, and its essential oil can also be play a key role in the preparation of specific microbiologic culture media for scientific research fields or for conservation procedures. Additionally, the production of essential oils with a constant chemical composition would be interesting.

\section{Acknowledgement}

The authors express their gratitude to Pr. Ladjama Ali, the director of Applied Biochemistry and Microbiology laboratory, department of Biochemistry, Annaba University, Algeria for his support.

\section{Funding Information}

This study was supported by grants from the Algerian Ministry of High Education and Scientific Research.

\section{Author's Contributions}

Barhouchi Badra: Conceived of the research, designed the study, drafted and revised the paper.

Aouadi Saoudi: Involved in study design, sample preparation, manuscript writing and scientific discussion.

Abdi Akila: Involved in antibacterial study and performed in the laboratory work.

\section{Ethics}

This article is original containing unpublished materials. All authors have read and approved the manuscript and no ethical issues involved.

\section{References}

AFES, 1995. Référentiel Pédologique. 1st Edn., Association Française de l'étude des sols, INRA, Paris, p: 329

Aboutabl, E.A., K.M. Meselhy, E.M. Elkhreisy, M.I. Nassar and R. Fawzi, 2013. Composition and bioactivity of essential oils from leaves and fruits of Myrtus communis and Eugenia supraxillaris (Myrtaceae) grown in Egypt. J. Essential Oil Bear. Plants, 14: 192-200. DOI: 10.1080/0972060X.2011.10643921

Adams, R.P., 2007. Identification of essential oil components by gas chromatograph/quadrupole mass spectroscopy. Allured Publishing, Carol Stream.
Aidi Wannes, W., B. Mhamdi and B. Marzouk, 2008. GC comparative analysis of leaf essential oils from two myrtle varieties at different phenological stages. Chromatographia. J., 69: 145-150. DOI: $10.1365 / \mathrm{s} 10337-008-0818-9$

Akin, M., A. Aktumsek and A. Nostro, 2010. Antibacterial activity and composition of the essential oils of Eucalyptus camaldulensis Dehn. and Myrtus communis L. growing in Northern Cyprus. Afr. J. Biotechnol., 9: 531-535. DOI: 10.5897/AJB09.1562

Amensour, M., S. Bouhdid, J. Fernundez-Lpez, M. Idaomar and N.S. Senhaji et al., 2010. Antibacterial activity of extracts of Myrtus communis against food-borne pathogenic and spoilage bacteria. Int. J. Food Propert., 13: 1215-1224.

DOI: $10.1080 / 10942910903013399$

Asllani, U., 2000. Chemical composition of Albanian myrtle oil (Myrtus communis L.). J. Essent. Oil Res., 12: $140-142$. DOI: 10.1080/10412905.2000.9699481

Ben Ghnaya, A., H. Chograni, C. Messoud and M. Boussaid, 2013. Comparative chemical composition and antibacterial activities of Myrtus communis L. essential Oils isolated from Tunisian and Algerian population. Plant. Pathol. Microbiol., 4: 186-186. DOI: 10.4172/2157-7471.1000186

Berka-Zougali, B., A. Hassani, C. Besombes and K. Allaf, 2010. Extraction of essential oils from Algerian myrtle leaves using instant controlled pressure drop technology. J. Chromatogr. A, 1217: 6134-6142. DOI: $10.1016 /$ j.chroma.2010.07.080

Boelens, M.H. and R. Jimenez, 1992. The chemical composition of Spanish myrtle oils. Part II. J. Essent. Oil. Res., 4: 349-353. DOI: 10.1080/10412905.1992.9698084

Bouzabata, A., F. Boussaha, J. Casanova and F. Tomi, 2010. Composition and chemical variability of leaf oil of Myrtus communis from north-eastern Algeria. Nat Prod Commun., 5: 1659-1662. PMID: 21121268

Cannas, S., P. Molicotti, M. Ruggeri, M. Cubeddu and M. Sanguinetti et al., 2013. Antimycotic activity of Myrtus communis L. towards Candida spp. from clinical isolates. J. Infect Dev. Ctries., 7: 295-298. DOI: $10.3855 /$ jidc. 2799

Cavallo, J.D., 2007. Comité de l'antibiogramme de la société française de microbiologie.

Chalchat, J.C., R.P. Garry and A. Michet, 1998. Essential oils of myrtle (Myrtus communis L.) of the mediterranean littoral. J. Essential Oil Res., 10: 613-617. DOI: 10.1080/10412905.1998.9700988

CLSI, 2006. Approved Standard M100-S12. NCCLS, methods for dilution antimicrobial susceptibility tests of bacterial that grow aerobically. Clinical Laborotory Standards Institute. 
Cox, S.D., C.M. Mann and J.L. Markham, 2001. Interactions between components of the essential oil of Melaleuca alternifolia. J. Applied Microbiol., 91: 492-497. DOI: 10.1046/j.1365-2672.2001.01406.x

Curini, M., A. Bianchi, F. Epifano, R. Bruni and L. Torta et al., 2003. Composition and in vitro antifungal activity of essential oils of Erigeron canadensis and Myrtus communis from France. Chem. Natural Compounds, 39: 191-194.

DOI: $10.1023 / \mathrm{A}: 1024818015122$

De Laurentis, N., A. Rosato, L. Gallo, L. Leone and M.A. Milillo, 2005. Chemical composition and antimicrobial activity of Myrtus communis. Rivista Italiana EPPOS, 39: 3-8.

Dell'Agli, M., C. Sanna, P. Rubiolo, N. Basilico and E. Colombo et al., 2012. Anti-plasmodial and insecticidal activities of the essential oils of aromatic plants growing in the Mediterranean area. Malaria J., 11: 219-219. DOI: 10.1186/1475-2875-11-219

Deriu, A., G. Branca, P. Molicotti, G. Pintore and M. Chessa et al., 2007. In vitro activity of essential oil of Myrtus communis L. against Helicobacter pylori. Int. J. Antimicrobial Agents, 30: 562-565. DOI: 10.1016/j.ijantimicag.2007.07.005

European Pharmacopeia, 2002. Council of Europe. Strasbourg Cedex, France.

Flamini, G., P.L. Cioni, I. Morelli, S. Maccioni and R. Baldini, 2004. Phytochemical typologies in some populations of Myrtus communis L. on Caprione Promontory (East Liguria, Italy). Food Chem., 85: 599-604. DOI: 10.1016/j.foodchem.2003.08.005

Gardeli, C., V. Papageorgiou, A. Mallouchos, K. Theodosis and M. Komaitis, 2008. Essential oil composition of Pistacia lentiscus L. and Myrtus communis L.: Evaluation of antioxidant capacity of methanolic extracts. Food Chem., 107: 1120-1130. DOI: 10.1016/j.foodchem.2007.09.036

Ghasemi, E., F. Raofie and N. Mashkouri-Najafi, 2010. Application of response surface methodology and central composite design for the optimisation of supercritical fluid extraction of essential oils from Myrtus communis L. leaves. Food Chem., 126: 1449-1453. DOI: 10.1016/j.foodchem.2010.11.135

Grayer, R.J. and J.B. Harborne, 1994. A survey of antifungal compounds from higher plants, 19821993. Phytochemistry, 37: 19-42.

DOI: 10.1016/0031-9422(94)85005-4

Jamoussi, B., M. Romdhane, A. Abderraba, B. Ben Hassine and A. El Gadri, 2005. Effect of harvest time on the yield and composition of Tunisian myrtle oils. Flavour. Fragrance. J., 20: 274-277.

DOI: $10.1002 / \mathrm{ffj} .1453$

Jerkovic, I., A. Radonic and I. Borcic, 2002. Comparative study of leaf, fruit and flower essential oils of Croatian Myrtus communis (L.) during a one-year vegetative cycle. J. Essential Oil Res., 14: 266-270. DOI: $10.1080 / 10412905.2002 .9699849$
Kivanc, M. and A. Akgul, 1986. Antibacterial activities of essential oils from Turkish spices and citrus. Flavour. Fragr. J., 1: 175-179. DOI: $10.1002 / \mathrm{ffj} .2730010409$

Mahboubi, M. and F. Ghazian Bidgoli, 2010. In vitro synergistic efficacy of combination of amphotericin B with Myrtus communis essential oil against clinical isolates of Candida albicans. Phytomedicine, 17: 771-774. DOI: 10.1016/j.phymed.2010.01.016

Messaoud, C., Y. Zaouali, A. Ben Salah, M.L. Khoudja and M. Boussaid, 2005. Myrtus communis in Tunisia: Variability of the essential oil composition in natural populations. Flavour Fragrance J., 20: 577-582. DOI: $10.1002 / \mathrm{ffj} .1490$

Mulyaningsih, S., F. Sporer, S. Zimmermann, J. Reichling and M. Wink, 2010. Synergistic properties of the terpenoids aromadendrene and 1,8-cineole from the essential oil of Eucalyptus globulus against antibiotic-susceptible and antibiotic-resistant pathogens. Phytomedicine, 17: 1061-1066.

DOI: 10.1016/j.phymed.2010.06.018

Nassar, M., E.A. Aboutabl, R.F. Ahmed, E.D.A. El-Khrisy and K.M. Ibrahim et al., 2010. Secondary metabolites and bioactivities of Myrtus communis. Pharmacognosy Res., 2: 325-329. DOI: $10.4103 / 0974-8490.75449$

O"zek, T., B. Demirci and K.H.C. Basera, 2000. Chemical composition of Turkish myrtle oil. J. Essential Oil Res., 12: 541-544. DOI: 10.1080/10412905.2000.9712154

Pepeljnjak, S., I. Kosalec, Z. Kalodera and N. Blazević, 2005. Antimicrobial activity of juniper berry essential oil (Juniperus communis L., Cupressaceae). Acta Pharm., 55: 417-423. PMID: 16375831

Prabuseenivasan, S., M. Jayakumar and S. Ignacimuthu, 2006. In vitro antibacterial activity of some plant essential oils. BMC Comple.. Altern. Med., 6: 39-39. PMID: 17134518

Randrianarivelo, R., S. Sarter, E. Odoux, P. Brat and M. Lebrun et al., 2009. Composition and antimicrobial activity of essential oils of Cinnamosma fragrans. Food Chem., 114: 680-684. DOI: 10.1016/j.foodchem.2008.10.007

Rasko, D.A., D.R. Webster, J.W. Sahl, A. Bashir and N. Boisen et al., 2011. Origins of the E. coli strain causing an outbreak of haemolytic-uremic syndrome in Germany. New England J. Med., 365: 709-717. DOI: 10.1056/NEJMoa1106920

Reichling, J., P. Schnitzler, U. Suschke and R. Saller, 2009. Essential oils of aromatic plants with antibacterial, antifungal, antiviral, and cytotoxic properties-an overview. Forsch Komplementmed, 16: 79-90. DOI: 10.1159/000207196 
Rosato, A., C. Vitali, N. De Laurentis and D. Armenise, 2007. Antibacterial effect of some essential oils administered alone or in combination with Norfloxacin. Phytomedicine, 14: 727-732. DOI: 10.1016/j.phymed.2007.01.005

Scora, R.W., 1973. Essential leaf oil variability in green, variegated and albino foliage of Myrtus communis. Phytochemistry, 12: 153-155.

DOI: $10.1016 / \mathrm{S} 0031-9422(00) 84637-3$

Senatore, F., C. Formisano, F. Napolitano, D. Rigano and M. Özcan, 2013. Chemical composition and antibacterial activity of essential oil of Myrtus communis L. growing wild in Italy and Turkey. J. Essential Oil Bear. Plants, 9: 162-169. DOI: 10.1080/0972060X.2006.10643489

Shu, C.K. and B.M. Lawrence, 1997. Reasons for the Variation in Composition of Some Commercial Essential Oils. In: Spices: Flavor Chemistry and Antioxidant Properties, Risch, S.J. and C.T. Ho (Eds.), ACS Symposium Series, Washington, DC, ISBN-10: 0841234957, pp: 138-159.

Smid, E.J. and L.G.M. Gorris, 1999. Natural Antimicrobials for Food Preservation. In: Handbook of Food Preservation, Rahman, M.S. (Ed.), CRC Press, ISBN-10: 0824702093, pp: 285-308.
Sofos, J.N., L.R. Beuchat, P.M. Davidson and E.A. Johnson, 1998. Naturally occurring antimicrobials in food. Regulatory Toxicol. Pharmacol., 28: 71-72. DOI: 10.1006/rtph.1998.1246

Tserennadmid, R., M. Tak, L. Galgczy, T. Papp and M. Pesti et al., 2011. Anti yeast activities of some essential oils in growth medium, fruit juices and milk. Int. J. Food Microbiol., 144: 480-486.

DOI: 10.1016/j.ijfoodmicro.2010.11.004

Tuberoso, C.I.G., A. Barra, A. Angioni, E. Sarritzu and F.M. Pirisi, 2006. Chemical composition of volatiles in Sardinian myrtle (Myrtus communis L.) alcoholic extracts and essential oils. J. Agric. Food. Chem., 54: 1420-1426. DOI: 10.1021/jf052425g

Zanetti, S., S. Cannas, P. Molicotti, P. Bua and M. Cubeddu et al., 2010. Evaluation of the antimicrobial properties of the essential oil of Myrtus communis L. against clinical strains of Mycobacterium spp. Interdiscip. Perspect. Infect. Dis. DOI: 10.1155/2010/931530

Zrira, S., A. Elamrani and B. Benjilali, 2003. Chemical composition of the essential oil of Pistacia lentiscus L. from Morocco-a seasonal variation. Flavour. Fragrance. J., 18: 475-480. DOI: 10.1002/ffj.1221 